\title{
The Impact of an Environmental Educational Program of a School Garden on Pupils with Intellectual Disabilities-A Comparative Approach
}

\author{
Alexandros Stavrianos' ${ }^{1}$, Alexia Spanoudaki ${ }^{2}$ \\ ${ }^{1}$ Faculty of Social Care \& Education, Anglia Ruskin University, Cambridge, England \\ ${ }^{2}$ Faculty of Preschool Education, University of the Aegean, Rhodes, Greece \\ Email: alex rds@hotmail.com
}

Received 4 March 2015; accepted 28 March 2015; published 31 March 2015

Copyright (C) 2015 by authors and Scientific Research Publishing Inc.

This work is licensed under the Creative Commons Attribution International License (CC BY). http://creativecommons.org/licenses/by/4.0/

(c) (;) Open Access

\begin{abstract}
The following research describes an attempt to combine environmental education through outdoor activities in Special Education. It examines the use of a school garden as a learning environment in Special Education by looking at the stances and opinions of 10 pupils, diagnosed with mild to moderate intellectual disability, towards Environmental Education and prognoses barriers that may occur in the learning process. Specifically, the study focuses on the skills and subject knowledge those students have cultivated through a project called "School Garden", highlighting the ideas pupils have, regarding the position of environmental education in their school curriculum. Using descriptive statistical analysis to compare the two groups of pupils, this research suggests the further practice of Environmental Education in Special Education. The research took place in two Special Education Primary Schools in Greece, while the data were collected using semi-structured interviews. The main conclusions of the research were that students who participated in their school's environmental educational program seem to be more familiarized with a range of concepts related to the environment and possess skills linked directly to Environmental Education in relation to their peers that did not engage in the project, while pupils who participated in the "School Garden", unlike their peers, perceived outdoor activities of their school as part of the learning process, in formal education. This study proposes further research to take place in the area of Environmental Education and Special Education.
\end{abstract}

\section{Keywords}

Biophilia, Environmental Education, Inclusion, Special Education, School Garden 


\section{Introduction}

The modern way of life limits the capability of exploration and interaction of man and his natural environment [1], while the needs of the trainees seem not to be covered by the traditional educational system [2]. In the past, environmental education was strictly related to the issue of survival. Man had to obtain knowledge about the behaviour of nature, to be protected from the elements present in nature, for the exploitation of natural resources, products and other goods. Over time, cultural and technological development, the concept of environmental education, began to diversify and expand the areas of learning and exploitation. This resulted in not only creating environment-related disciplines but also to a deeper study of individual research areas. Furthermore, the involvement of people in these areas of science and their systematic activation contributed to the "expansion of knowledge, greater experience, better understanding of the nature and socio-cultural progress" [3]. The last decade there is an increased interest for the use of school gardens for educational reasons and a try for their inclusion into the curriculum [4] [5]. A school garden has been described as a complex reality but also as a frame that morphs the relation with the child who experiences it, since it can provide the child with opportunities of exploration and connection to the natural, cultural, historical and social inheritance of its community [6].

The main purpose of this study was to investigate the impact of the environmental educational program of a School Garden had on pupils with disabilities. Even though, the use of school gardens in educational practice is often limited, possibly due to the fact that outdoor educational practice is not considered to be a real educational process, while teaching outdoors has been said to produce insecurity and uncertainty to the teachers [7].

Despite current political notions for the deconstruction of special education and the construction of inclusion [8], environmental education in special schools, must be approached differently from environmental education in mainstream schools [9]. This study was conducted in two special schools in a try to explore the relationship of Environmental Education and Special Education, since the use of the first in Special Education is not common in Greece, while their combination stimulates questions about the usefulness of Environmental Education in Special Education, the relationship that exists between them as well as the role it plays to pupils labelled as special [10].

A study from Kaplan \& Kaplan [11] claimed that man is attracted by the outdoor natural environment and acts efficiently within it, perhaps because these were the environments of his survival and development for many years. Additional studies, like Bauer [12] or Green [13] claim the existence of a natural, historically or culturally, positive trend towards the natural environment, and even also suggest the existence of a collective environmental thinking during early childhood.

Previous studies [14] have indicated the existence of psychological and physiological connections between man and his natural surroundings, while others [11] [15] examine the preference of people towards areas with vegetation, which strengthen self-respect and interpersonal relationships.

\section{Method of Research}

The study took place within two special schools of primary education in Greece within the same area. In school A, the students were involved in an environmental educational program titled "School Garden" the school year of 2010-2011, while in School B, the students had never participated in a similar program within formal education. In total the study contained two phases; phase a, in which general information were gathered through conversations with the teaching staff, and also phase $\mathrm{b}$, during which the main data collection occurred.

The sample of this research consists of two groups. Group A, in School A, consists of 3 boys and 2 girls who experienced the environmental educational program "School Garden" while Group B, in School B, consists of 3 boys and 2 girls who never experienced any environmental educational program in their school, Both pupils of the school were 10 years old while they were all diagnosed with cognitive difficulties and in more detail, they were characterized as, moderate to mild, intellectually disabled. The research in phase a, started from April 2012 during which 5 meetings with members of the teaching staff occurred. During the meetings the questions of phase $b$ research were discussed and the sample was recruited. The research in phase $b$, was conducted using semi structured questionnaires, which were given to pupils who were selected by the teaching staff of the schools, using their own criteria, which included interest and availability to participate in the upcoming research, as well as their belief of the children's capacity to give informed consent, through the form of individualized semi structured interviews, since many of those pupils were not able to read or write.

The parents of the students were informed about the research and gave informed consent verbally for their 
children to take part in the research, moreover the pupils who participated in the research were informed for its purpose and aims and asked if they wanted to participate in the interviews. To avoid neutrality and in a try to locate positive or negative stances from the sample, the answers were coded using a 4 point Likert Scale (I Strongly Agree, I Agree, I Strongly Disagree, I Disagree), while the data were analyzed descriptively, by comparing the frequencies of the answers the pupils of both groups. To avoid any potential risk of interfering with the teaching procedures, the interviews took place gradually, in November and December of 2012, while each of them lasted for less than 20 minutes.

\section{Findings}

From Table 1, while we do not notice any differences in stances towards environmental issues, the group of pupils who were taught through the project of "School Garden" seem to consider outdoor learning as part of a formal learning process. In more detail $80 \%$ of the pupils who participated in the program prefer to have the class outdoors, unlike the $60 \%$ of the pupils who did not participate in the program. Moreover, all pupils taught through the project agree that "I learn how to use different tools in a school garden".

In Figure 1, one can notice that students who participated in the project seem to have acquired more skills and knowledge when compared to pupils who did not participate in the project. In more detail, $40 \%$ of them is familiarized with fertilizers while $60 \%$ of them claim that trees and plants are able to produce their own food and has thought of choosing a profession related to gardening, while all pupils of Group A claim that they care for the environment better than they used to. On the other hand, none of the pupils of Group B is familiarized with the term "fertilizer" while only 1 of them has thought of following a profession in relation to gardening. Both groups of students feel able to cultivate plants and exercise gardening.

In Figure 2 one can notice that in principle, pupils who participated in the environmental project of "School Garden" seem to use more sources of information when compared to students who never participated in a similar project. In more detail, when we compare the two groups, we notice that $20 \%$ more pupils in Group A,

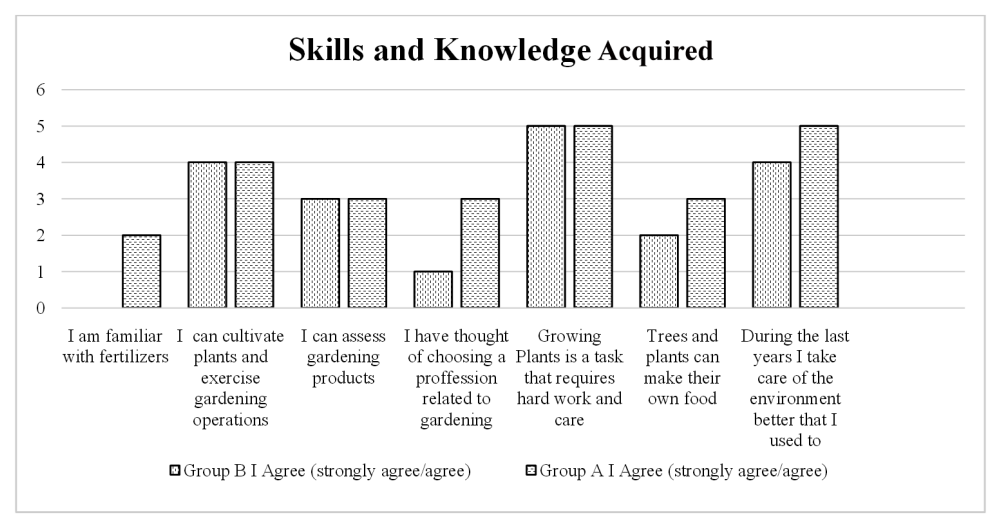

Figure 1. Comparison of answers given on the subject of Skills and Knowledge Acquired related to environmental education.

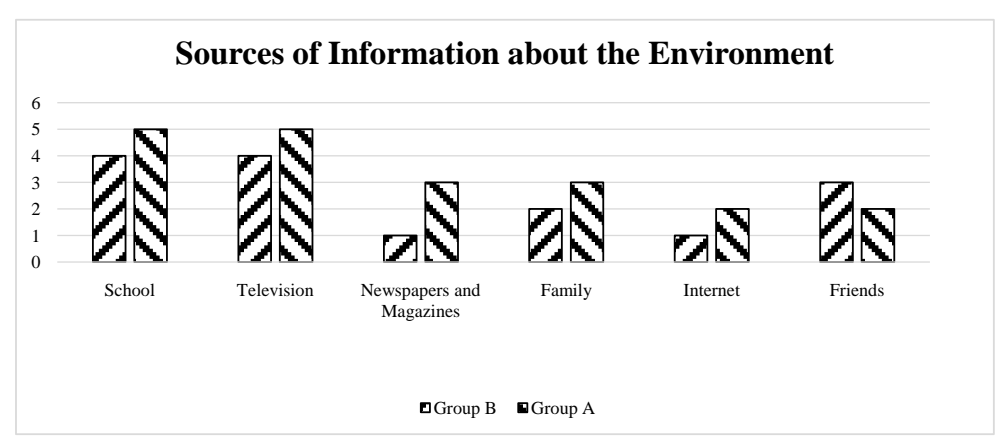

Figure 2. Comparisons on answers given regarding "Sources of Information about the Environment”. 
Table 1. Stances and opinions about the environment.

\begin{tabular}{ccc}
\hline & \multicolumn{1}{c}{ I Agree (Strongly Agree/Agree) } \\
\cline { 2 - 3 } Statement & Group B Percentage \% & Group A Percentage \% \\
\cline { 2 - 3 } We should protect the environment & 100 & 100 \\
We should recycle & 100 & 60 \\
We should use alternative sources of energy & 60 & 0 \\
We should spent natural resources without thinking & 0 & 80 \\
I prefer classes outdoors & 60 & 60 \\
A school garden can help me professionally & 40 & 100 \\
I learn how to use different tools in a school garden & 60 & 100 \\
A school garden is directly linked to class & 60 & 00 \\
\hline
\end{tabular}

use school, television, discussions with their family and the internet to get informed about environmental issues, while $40 \%$ more use newspapers and magazines. $20 \%$ more students who were not engaged in the environmental educational program use discussions with their friends to get informed about environmental issues.

\section{Discussion}

Pupils in group A, who participated in the environmental education program of "School Garden" seem to have in general a deeper understanding of concepts related to the environment compared to the answers the students of group B. Another noticeable fact is that the students in group A were also thinking to follow a profession related to the project they were taught. Rivkin [16] claims that residents in heavily populated cities and especially children, need daily interaction with nature. Perhaps this conclusion is a claim of support towards the "Biophilia Hypothesis" case suggested by Kellert [17]. According to this, man needs interaction with his natural surroundings in the same way interaction with other people is essential to him for his own development. In reality, through this matrix of interactions, the trainee approaches reality from his own perspective and acquires identity and goal [13]. It should be noted that this investigation only concerns 2 groups of students of 2 special schools and given the fact that pupils of that particular area have different demographic characteristics as well as different lifestyles, cannot be generalized. This study also investigates opinions and stances of 10 pupils who were taught through the environmental project of "School Garden" in the school year of 2010-2011 and compares them to stances and opinions of pupils who were not engaged, within formal education, to a similar project. Therefore, this study refers to a particular program of Environmental Education and not to its entire spectrum. One more limitation of the above research is the use of comparative statistical analysis in small size sample.

\section{Conclusions}

The interdisciplinary approach as well as the social and paraprofessional skills that can be developed by children with moderate to severe learning difficulties, through their work with a School Garden is a crucial implication of the above research, while the findings suggest that this case study is generally supportive of claims that outdoor learning and environmental education can facilitate positive affective development.

In more detail, the children who participated in the environmental educational program seem more potent to develop a basic conceptual frame regarding plants and gardens, realize the interactive relationship between natural and anthropogenic environment, practice on observation and on information collection, as well as to work on possible solutions regarding issues about plants and gardens (Figure 1). Formal and informal education seem to be the primary source of information regarding the environment, to pupils with learning disabilities (Figure 2), while the program seems to cultivate awareness on challenging issues regarding complex concepts such as sustainability and environmental ethics, while the application of the School Garden program seem to make pupils who took part in it open to the idea that outdoor learning, can be part of formal education (Table 1). Due to the 
above conclusions as well as the limitations of the above study, we suggest further in depth research to take place in the area.

\section{References}

[1] Malone, K. and Tranter, P. (2003) School Grounds as Sites for Learning: Making the Most of Environmental Opportunities. Environmental Education and Research, 9, 283-303. http://dx.doi.org/10.1080/13504620303459

[2] Smith, A.G. (2007) Place-Based Education: Breaking through the Constraining Regularities of Public School. Environmental Education Research, 13, 189-207. http://dx.doi.org/10.1080/13504620701285180

[3] Metochianakis (2006) Introduction to Pedagogy, B'. Metochianakis, Heraklion.

[4] Bell, A.C. (2001) The Pedagogical Potential of School Grounds. In: Grant, T. and Littlejohn, G., Eds., Greening School Grounds: Creating Habitats for Learning, New Society Publishers, Gabriola Island, 9-11.

[5] Coffey, A. (2001) Transforming School Grounds. In: Grant, T. and Littlejohn, G., Eds., Greening School Grounds: Creating Habitats for Learning, New Society Publishers, Gabriola Island, 2-5.

[6] Germanos, D. (2001) Space and Teaching Procedures. Gutenberg, Athens.

[7] Skamp, K. and Bergmann, I. (2001) Facilitating Learnscape Development, Maintenance and Use: Teacher’s Perceptions and Self-Reported Practice. Environmental Education Research, 7, 333-358. http://dx.doi.org/10.1080/13504620120081241

[8] Tomas, G. and Loxley, A. (2001) Deconstructing Special Education and Constructing Inclusion. Open University Press, Buckingham.

[9] Chapman, N. and Pease, L. (2006) Special Environmental Education for the Learning Disabled. Environmental Education and Awareness, 1, 169-188.

[10] Liarakou, G. (2002) Environmental Education: A Tool for Inclusion of Pupils with Special Needs in Mainstream Education. Sychroni Ekpaideusi, 124, 104-110.

[11] Kaplan, R. and Kaplan, S. (1989) The Experience of Nature: A Psychological Perspective. Cambridge University Press, New York.

[12] Bauer, P.J., Dow, G.A., Bittinger, A.A. and Wenner, J.A. (1998) Accepting and Exempting the Unexpected: 30Month-Olds' Generalization of Event Knowledge. Cognitive Development, 13, 421-452. http://dx.doi.org/10.1016/S0885-2014(98)90002-8

[13] Green, M. (2007) Food Gardens: Cultivating a Pedagogy of Place. Gippsland AARE Conference, Monash University, Fremantle.

[14] Chawla, L. (1994) Gardening as an Initiation into Environmental Action. American Horticulturist, 73, 6-78.

[15] Lohr, V.I. and Relf, P.D. (2000) An Overview of the Current State of Human Issues in Horticulture in the United States. Hort Technology, 10, 27-33.

[16] Rivkin, M. (1997) The School Yard Habitat Movement: What It Is and Why Children Need It. Early Childhood Education Journal, 25, 61-66. http://dx.doi.org/10.1023/A:1025694100870

[17] Kellert, S. (1993) Introduction. In: Kellert, R.S. and Wilson, E.O., Eds., The Biophilia Hypothesis, Island Press/Shearwater, Washington DC. 